\title{
CURSO DE MESTRADO EM EDUCAÇÃO FÍSICA NA USP
}

\author{
Alberto Carlos Amadio*
}

A Escola de Educação Física da Universidade de Sāo Paulo foi criada pelo decreto estadual 4855 de 27/01/31 e iniciou suas atividades em Agosto de 1934. Foi incorporada ao sistema estadual de ensino superior em Dezembro de 1958. Passou a integrar a Universidade de São Paulo em Dezembro de 1969. Instalou-se no "campus" da Cidade Universitária Armando de Salles Oli- veira em Março de 1975, onde conta com uma área de aproximadamente $9500 \mathrm{~m}^{2}$

Entre os objetivos da Escola consta o de formação de profissionais em todos os ramos da Educação Física, promovendo, administrando, de senvolvendo e aperfeiçoando o ensino na Educaçāo Física. Demonstramos através da Tab. 010 volume e a distribuição de profissionais capacita-

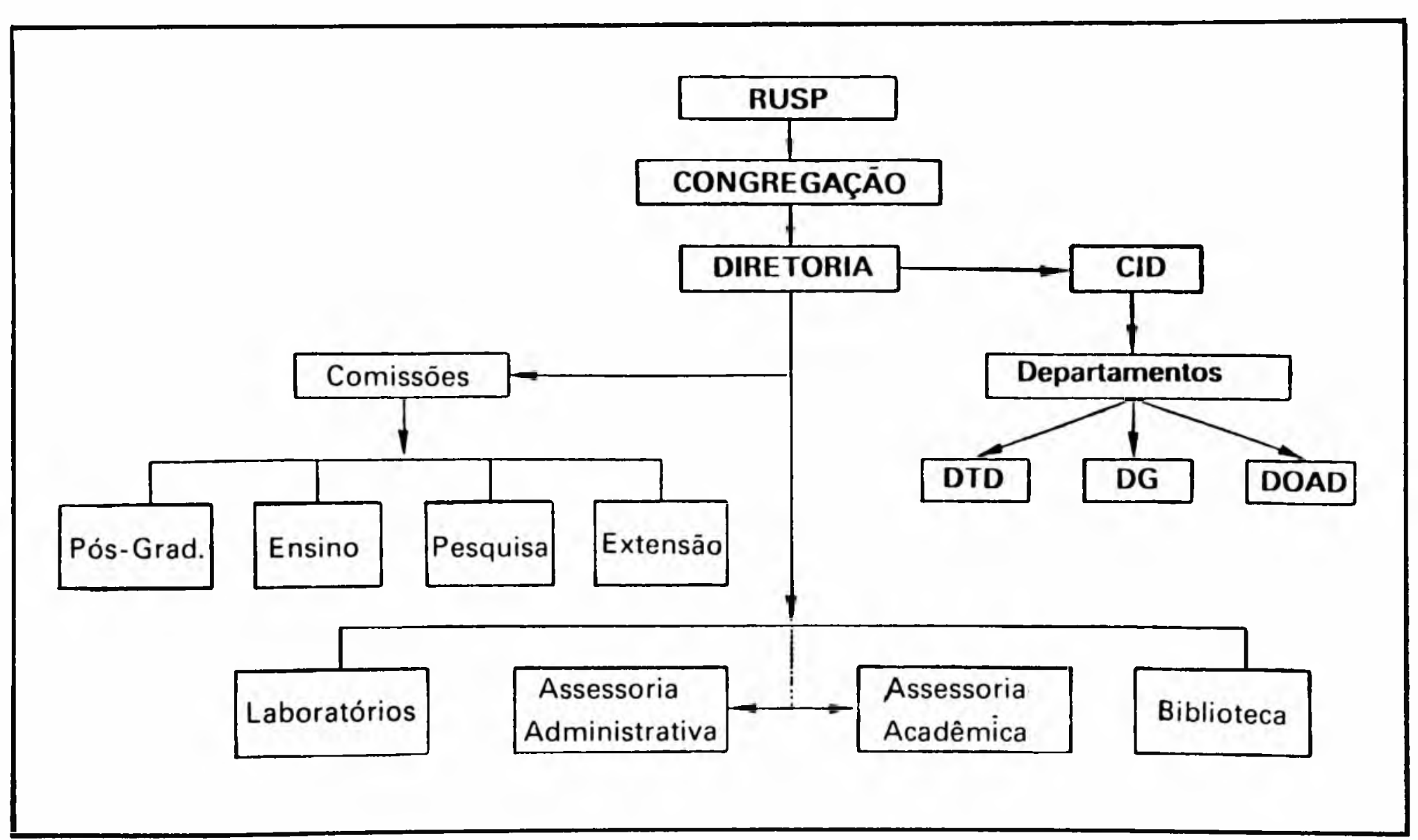

Fig. 01: Organograma funcional da Escola de Educação Física da Universidade de São Paulo.

Professor Assistente Doutor da disciplina de Cinesiologia, EEF-USP

Rev. Paul. Educ. Fís., São Paulo, 2 (2): 37 40, maio 1988. 
Tabela 01: Demonstrativo de formados pela Escola de Educação Física no periodo de 1935 a 1987 em todos os cursos oferecidos.

\begin{tabular}{|l|r|c|}
\cline { 2 - 2 } \multicolumn{1}{c|}{} & [n] & {$[\%]$} \\
\hline LICENCIATURA & 2506 & 50.9 \\
\hline TÉCNICAS DESPORTIVAS & 1702 & 34.6 \\
\hline MEDICINA ESPECIALIZADA & 272 & 5.5 \\
\cline { 1 - 2 } ADMINISTRAÇÃO EM ED.FÍSICA & 198 & 4.0 \\
\cline { 1 - 2 } NORMALISTA ESPECIALISTA & 129 & 2.6 \\
\cline { 1 - 2 } MESTRADO & 70 & 1.5 \\
\cline { 1 - 2 } MASSAGISTA & 47 & 0.9 \\
\hline
\end{tabular}

dos pela escọla nas diversas áreas da Educação Física no período de 1935 a 1987.

Demonstramos de forma esquemática o atual organograma de estrutura funcional da Escola (Fig. 01), para as áreas de Ensino, Pesquisa e Administração onde pode-se observar a localização da Comissão de Pós-Graduação que possui a responsabilidade funcinal do Curso de Mestrado em Educação Física.

\section{CURSO DE MESTRADO EM EDUCAÇÃO FÍSICA}

O curso de Pós-Graduação da Escola de Educação Física, o primeiro a ser instituído na América Latina, teve seu início em Março de 1977. com um programa de Mestrado, na área de Educação Física, sendo destinado basicamente a capacitação de docentes para o ensino superior assim como promover o desenvolvimento de conhecimentos na área da Educação Física, através de

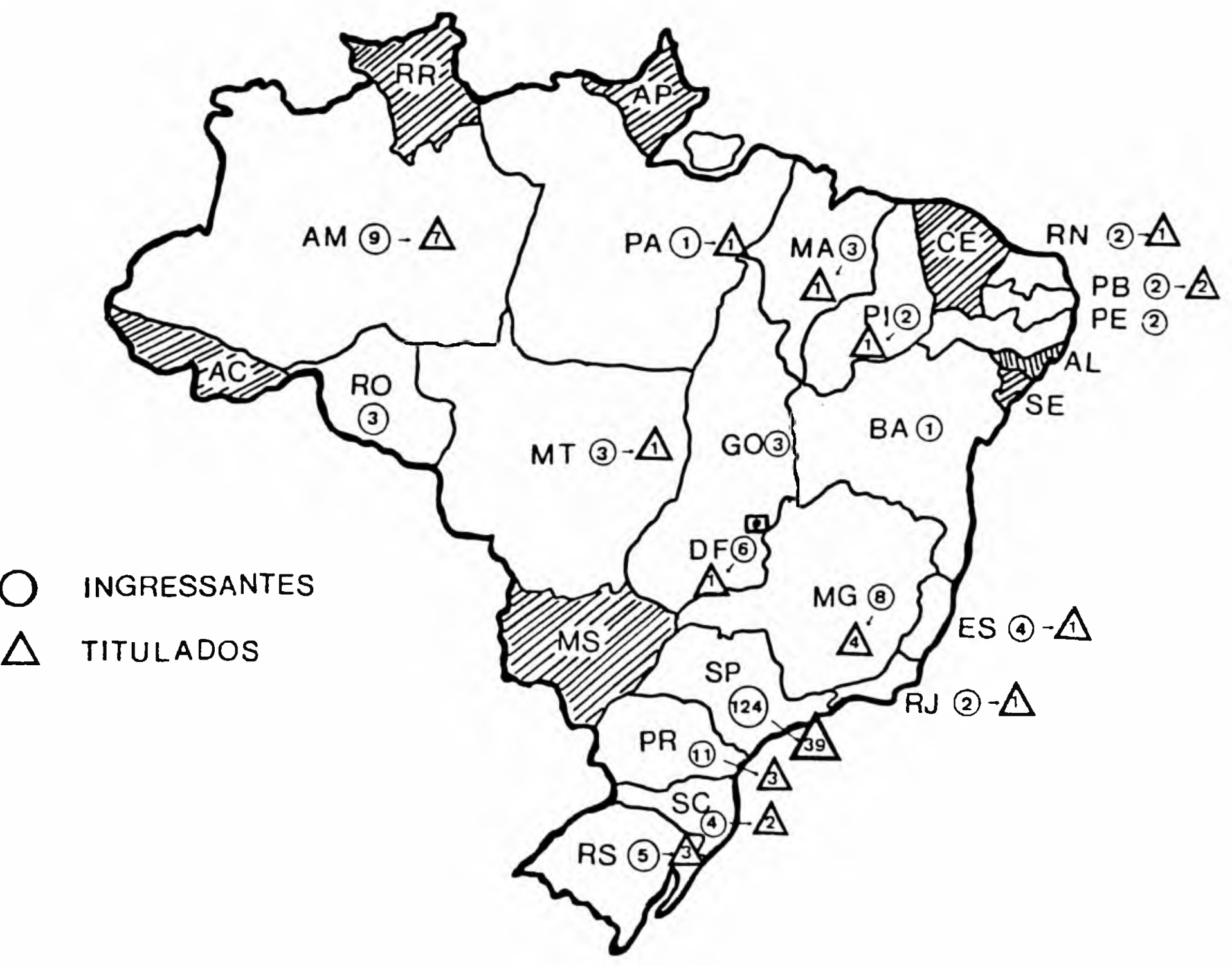


TAB. 02: Distribuição e Fluxo de Alunos do Curso de Mestrado em função do ano letivo (Período: 1977 a 1988), (Situação: Março de 1988).

\begin{tabular}{|c|c|c|c|}
\hline Ano & $\begin{array}{c}\text { Ingressantes } \\
(\mathbf{n})\end{array}$ & $\begin{array}{c}\text { Titulados } \\
\text { (n) }\end{array}$ & $\begin{array}{c}\text { Desistentes e/ou } \\
\text { Desligados } \\
\text { (n) }\end{array}$ \\
\hline 1977 & 30 & - & 2 \\
1978 & 18 & - & 1 \\
1979 & 13 & 2 & 1 \\
1980 & 20 & 3 & 1 \\
1981 & 15 & 9 & 1 \\
1982 & 16 & 3 & 6 \\
1983 & 15 & 9 & 1 \\
1984 & 16. & 13 & 3 \\
1985 & 14 & 10 & 7 \\
1986 & 15. & 9 & 2 \\
1987 & 20. & 12 & 3 \\
1988 & 10. & 3 & $28(14 \%)\left[{ }^{*}\right]$ \\
\hline TOTAL & $202(100 \%)$ & $73(36 \%)$ & $\cdots$ \\
\hline
\end{tabular}

[*] 14 Bolsistas dos Programas PICD e/ou Demanda Social CAPES/MEC

qualificação com bases Metodológica-Científica em Educação Física e Esportes.

A orientação das "Linhas de Pesquisa" onde concentram-se as disciplinas bem como a orientação das Dissertações de Mestrado, encontram-se assim distribuidas pelos Departamentos, conforme estrutura funcional da Escola.

A. Departamento Técnico-Desportivo:

A.1 Condicionamento físico

A.2 Desempenho Desportivo

A.3 Psicologia dos esportes

A.4 Biomecânica do esporte

A.5 Fisiologia do exercício

B. Departamento de Organização e Aplicacāo Desportiva

B.1 Nutrição e metabolismo relacionado a Educação física

B.2 Medidas e avaliação em Educação Física e esportes

B.3 Administração em Educação Física e esportes

B.4 Preparação profissional em Educação Física, Esportes, Recreação e Dança

B.5 Recreação e Lazer

C. Departamento de Ginástica.

C.1 Aprendizagem motora

C.2. Processo Ensino-aprendizagem em Educação Física, Esportes, Recreação e Dança
C.3 Desenvolvimento Motor

C.4 Crescimento e Desenvolvimento humano
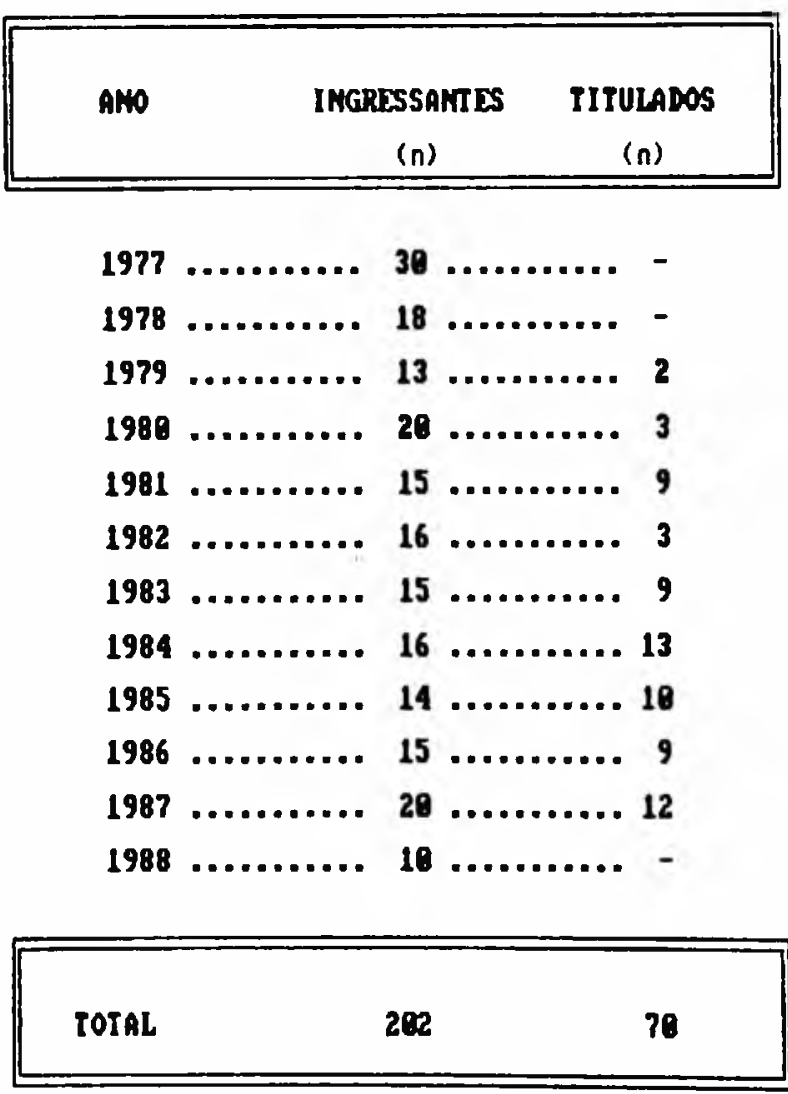

Fig. 02: Procedência dos alunos Ingressantes e correspondentes Titulados (1977 a 1988). 
$\mathrm{Na}$ Tab. 02 podemos observar a relação ingressantes e titulados fazendo a distribuição em função do ano letivo para o período de 1977 a 1988. A partir desta relação demonstra-se uma produção de dissertações ainda modesta (34.6\% do total de ingressantes), considerando-se porém que muitos dos ingressantes ainda estão em andamento com seus trabalhos pois encontram-se dentro dos prazos regulamentares da orientação do Curso.

Através da Fig. 02 podemos observar a relação ingressantes e titulados em função da procedência considerando-se as Universidades de origem pelos estados da Federação para o período de 1977 a 1988.
Pode-se ainda disrtribuir os ingressantes em funçāo da origem, referente ao período de 1977 a 1988, em dois Grupos: (I) Ingressantes pertencentes a Universidade e/ou Instituições de ensino do Estado de São Paulo ( $n=124,61.4 \%$ ) e (II) Ingressantes pertencentes a Universidades e/ou Instituições de ensino de outros estados ou países ( $n=78,38.6 \%)$.

Através da Fig. 03 apresentamos a distribuição das Dissertações defendidas por ano, para o período de 1979 a 1987 e respectiva porcentagem de incidência de produçāo no ano a partir do total das dissertações defendidas $(n=70)$. Observamos ainda que o ano de maior produção fora $1984 \mathrm{com}$ 13 dissertações defendidas $(18.6 \%)$.

\section{CURSO DE PÓS-GRADUAÇÃO MESTRADO Dissertações defendidas (1979 a 1987)}

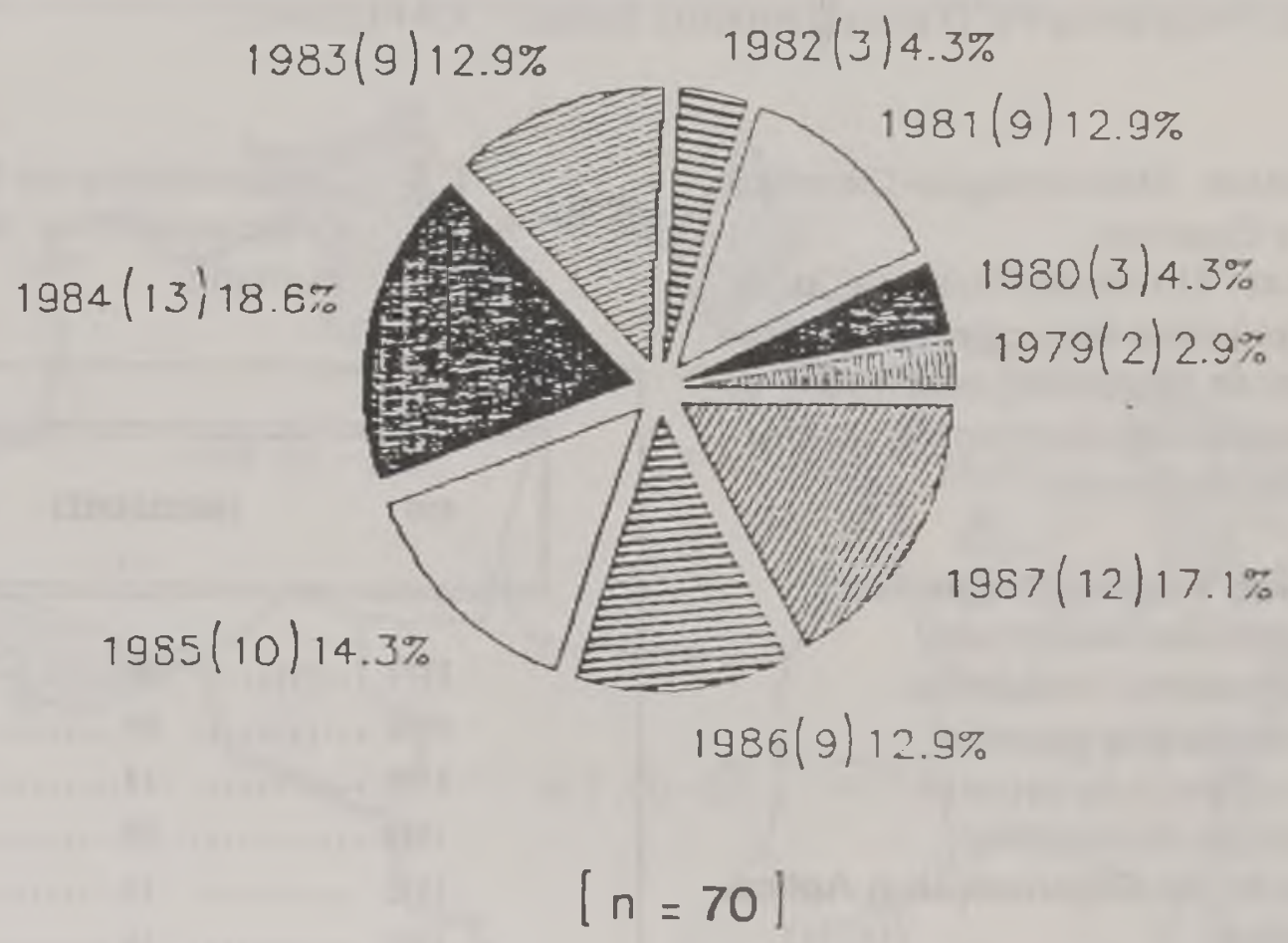

Fig. 03: Distribuição das Dissertaçōes defendidas (n) em função do ano letivo e respectiva porcentagem (\%) para o período 1979 a 1987. 